\title{
PENGEMBANGAN WISATA SEBAGAI DAYA TARIK SITUS RUMAH SANDI DI PERBUKITAN MENOREH KULON PROGO
}

\author{
Temoteus Prasetyo Hadi Atmoko \\ Prodi Perhotelan \\ Akademi Pariwisata Yogyakarta \\ prasplg@gmail.com
}

\begin{abstract}
ABSTRAK
Penelitian ini bertujuan untuk mengetahui bagaimana pengembangan wisata sebagai daya tarik situs Rumah Sandi di Perbukitan Menoreh Kulon Progo. Penelitan ini menggunakan metode penelitian deskriptif kualitatif. Hasil penelitian ini didapat strategi yang dapat disusun dalam pengembanagn situs Rumah Sandi yaitu penambahan jumlah sumberdaya manusia, pengidentifikasian para stakeholder sebagai mitra dalam pengembangan situs Rumah Sandi agar mampu beradaptasi dan dapat memenuhi kebutuhan pendidikan secara optimal, peningkatan kesadaran masyarakat terkait situs Rumah Sandi dan pelestariannya serta peningkatan kualitas pelayanan dengan merencanakan dan merumuskan sesuai kebutuhan pendidikan.
\end{abstract}

Kata kunci: Daya Tarik, Pariwisata, Pengembangan

\section{DEVELOPMENT OF TOURISM AS ATTRACTION OF SITUS RUMAH SANDI IN MENOREH HILL KULON PROGO}

\section{ABSTRACT}

This study aims to find out how tourism is developed as an attraction for Situs Rumah Sandi in Menoreh Hills Kulon Progo. This research uses descriptive qualitative research methods. The results of this study obtained a strategy that can be developed in developing the Situs Rumah Sandi, namely increasing the number of human resources, identifying stakeholders as partners in developing Situs Rumah Sandi to be able to adapt and be able to meet education needs optimally, increase public awareness about Situs Rumah Sandi and their preservation and improving service quality by planning and formulating according to educational needs.

Keywords: Attraction, Development, Tourism

\section{PENDAHULUAN}

Indonesia merupakan negara yang memiliki banyak potensi wisata berupa wisata alam, sejarah dan budaya. Keadaan alam, flora, fauna, peninggalan sejarah, seni dan budaya yang dimiliki Indonesia merupakan sumberdaya modal pembangunan kepariwisataan. Industri pariwisata yang berkembang dengan pesat akan memberikan pemahaman budaya melalui interaksi pengunjung wisata dengan masyarakat lokal tempat wisata tersebut. Melalui interaksi ini wisatawan akan mengenal dan menghargai budaya setempat.

Museum sebagai tempat melestarikan peninggalan sejarah merupakan bagian dari pariwisata yang menjunjung nilai- nilai budaya. Menurut Budiawan, seperti yang dikutip dalam harian haluan pada tanggal 18 Februari 2016, bahwa para pengelola museum dan sekolah perlu bersinergi meningkatkan minat siswa terhadap mata 
pelajaran sejarah nusantara yang belakangan ini mengalami penurunan. Rendahnya minat para pelajar terhadap mata pelajaran sejarah nusantara disebabkan belum adanya sinergi antara pengelola lembaga pendidikan dengan museum. Selain itu, hingga saat ini masih banyak pengajar yang menyampaikan materi sejarah dengan metode klasik atau tekstual. Seharunya penyampaian materi sejarah saat ini bisa lebih dinamis dengan meningkatkan kunjungan ke museum. Menurunnya minat berkunjung ke museum tersebut ditindak lanjuti oleh Pemerintah Provinsi Daerah Istimewa Yogyakarta (DIY). Sinergi antara sekolah dan museum telah difasilitasi oleh Dinas Kebudayaan DIY melalui program wajib kunjung museum bagi siswa SD dan SMP. Dengan demikian program tersebut akan sangat efektif dalam membantu mengedukasi siswa serta menumbuhkan kecintaan masyarakat terhadap museum.

Saat ini Rumah Sandi banyak dikunjungi oleh siswa PAUD, TK, SD, SLB, SMP, SMA dan wisatawan umum untuk mempelajari situs Rumah Sandi sebagai cikal bakal Sandi Negara yang berada di perbukitan Menoreh, Dusun Dukuh, Desa Purwoharjo, Samigaluh, Kulon Progo. Situs Rumah Sandi ini diresmikan pada tanggal 29 Januari 2014 oleh Gubernur Daerah Istimewa Yogyakarta dan Kepala Sandi Negara. Rumah Sandi ini dikelola oleh Museum Sandi Yogyakarta yang bertempat di Kota Baru Yogyakarta. Pengelolaan situs budaya dan benda bersejarah di Rumah Sandi dikembangkan sedemikian rupa sehingga menarik wisatawan. Dalam hal ini, perlu adanya kerjasama antara pengelola situs budaya rumah Sandi.

Berdasarkan penjabarandi atas rumusan masalah dalam penelitian ini adalah:

1. Bagaimana daya tarik wisata Rumah Sandi di Perbukitan Menoreh Kulon Progo?

2. Bagaimana analisis faktor pendukung dan penghambat Rumah Sandi di Perbukitan Menoreh Kulon Progo?
3. Bagaimana pengembangan wisata situs Rumah Sandi di perbukitan Menoreh Kulon Progo?

Tujuan Penelitian ini adalah:

1. Untuk mengetahui bagaimana daya tarik wisata Rumah Sandi di Perbukitan Menoreh Kulon Progo.

2. Untuk mengetahui bagaimana analisis faktor pendukung dan penghambat Rumah Sandi di Perbukitan Menoreh Kulon Progo.

3. Untuk mengetahui bagaimana pengembangan wisata situs Rumah Sandi di perbukitan Menoreh Kulon Progo.

Manfaat teoretis yang diperoleh dari penelitian ini adalah untuk menambah pengetahuan di bidang pariwisata. Sedangkan manfaat praktis yang dapat diperoleh melalui penelitian ini adalah sebagai strategi pengembangan wisata situs Rumah Sandi.

\section{LANDASAN TEORI Pariwisata}

Menurut Soekadijo dalam Widyaningsih (2013, hlm. 3) kata pariwisata berasal dari bahasa Sansakerta yang terdiri atas dua suku kata, yaitu pari dan wisata. Pari berarti seluruh, semua dan penuh. Wisata berarti perjalanan. Dengan demikian pariwisata dapat diartikan sebagai perjalanan penuh, yaitu berangkat dari suatu tempat, menuju dan singgah di suatu tempat, dan kembali ke tempat asal. Sedangkan menurut Sinaga (2010, hlm.12) pariwisata adalah suatu perjalanan dari satu tempat ke tempat lainnya yang sifatnya hanya sementara.

Pendidikan dan pariwisata merupakan dua hal yang berbeda, tetapi keduanya dapat saling bersinergi dan saling melengkapi. Proses pendidikan yang dilaksanakan dalam aktivitas wisata merupakan alternatif metode belajar yang efektif. Aktivitas wisata edukasi dapat menjadi sarana bersosialisasi dan menumbuhkan rasa kebanggaan serta kecintaan terhadap budaya dan bangsa. Wisata edukasi merupakan aktivitas pariwisata yang dilakukan wisatawan bertujuan untuk memperoleh pendidikan dan 
pembelajaran (Tim Pengabdian STP ARS 2017, hlm. 25).

Berdasarkan pendapat di atas, pariwisata edukasi dapat disimpulkan sebagai segala kegiatan dalam masyarakat yang berhubungan dengan pendidikan. Semua kegiatan berkunjung untuk mempelajari cagar budaya, pembuatan pusat rekreasi, penyelenggaraan pekan pariwisata dan sebagainya semua itu dapat disebut kegiatan pariwisata sepanjang dengan kegiatankegiatan itu semua dapat diharapkan para wisatawan akan datang untuk belajar.

\section{Jenis-Jenis Wisata Edukasi}

Menurut Purnawan (2012, hlm. 6) di Indonesia ada beberapa jenis wisata edukasi, diantaranya adalah:

1. Wisata edukasi sciencel ilmu pengetahuan

Wisata edukasi science atau ilmu pengetahuan adalah wisata edukasi yang berbasis kepada pendidikan ilmu pengetahuan.

2. Wisata edukasi sport

Adalah wisata edukasi yang berbasis kepada pendidikan secara fisik.

3. Wisata edukasi culture/ kebudayaan Wisata edukasi culture/ kebudayaan yang ada di Indonesia saat ini antara lain seni dan adat istiadat masyarakat setempat.

4. Wisata Edukasi Agrobisnis

Merupakan wisata edukasi yang berbasis pada pendidikan agro atau pertanian dan peternakan yang juga merupakan bisnis dari suatu perusahaan maupun perseorangan.

\section{Pengembangan Destinasi Wisata}

Destinasi Pariwisata menurut UU nomor 10 tahun 2009 adalah kawasan geografis yang spesifik berada dalam satu atau lebih wilayah administratif yang di dalamnya terdapat kegiatan kepariwisataan dan dilengkapi dengan ketersediaan daya tarik wisata, fasilitas umum, fasilitas pariwisata, aksesibilitas, serta masyarakat yang saling terkait. Menurut Hadiwijoyo (2012, hlm. 49) Obyek daya tarik wisata sebagai suatu bentukan dan fasilitas yang saling berhubungan dan menjadi alasan wisatawan mengunjungi suatu daerah tertentu. Obyek wisata tersebut yaitu:

1. Obyek wisata alam atau lingkungan (ekowisata).

2. Obyek wisata sosial budaya.

3. Obyek wisata minat khusus (special interest).

Sedangkan obyek daya tarik wisata menurut Sunaryo (2013, hlm.159) adalah kerangka pengembangan destinasi pariwisata terdiri dari komponen-komponen utama sebagai berikut:

1. Obyek daya tarik wisata (Attraction) mencakup keunikan dan daya tarik berbasis alam, budaya maupun buatan.

Atraksi yang menarik wisatawan terdiri dari 3 komponen yaitu:

a. Natural Resources (alami) seperti gunung, pantai, danau dan bukit.

b. Atraksi wisata budaya seperti arsitektur rumah tradisional, situs arkeologi, seni dan kerajinan, ritual, festival, kehidupan sehari hari, keramahan dan makanan lokal.

c. Atraksi buatan seperti acara olah raga, berbelanja, pameran, konferensi dan lain-lain.

2. Aksesibilitas (aksesibility) mencakup kemudahan sarana dan sistem transportasi. Faktor faktor aksesibilitas meliputi petunjuk arah, bandara, terminal, waktu yang dibutuhkan, biaya perjalanan, frekuensi transportasi menuju lokasi wisata dan perangkat lainnya.

3. Amenitas (amenities) mencakup fasilitas penunjang dan pendukung wisata. Amenities meliputi serangkaian fasilitas untuk memenuhi kebutuhan akomodasi, penyediaan makanan dan minuman, tempat hiburan, tempat-tempat perbelanjaan dan layanan lainnya.

4. Fasilitas umum (ancilary service) yang mendukung kegiatan pariwisata, seperti tersedianya sarana dan fasilitas umum yang mendukung tempat wisata.

5. Kelembagaan (institusions) yang memiliki kewenangan, tanggung jawab dan peran dalam mendukung terlaksananya kegiatan pariwisata. 
Komponen pelaku usaha maupun pemangku kepentingan pengembangan kepariwisataan adalah:

a. Pemerintah pusat dan daerah.

b. Swasta atau industri pariwisata.

\section{METODE}

Penelitan ini menggunakan metode penelitian deskriptif kualitatif. Menurut Komariah dan Satori (2011, hlm.23) penelitian kualitatif dilakukan karena peneliti ingin mengeksplor fenomenafenomena yang tidak dapat dikuantifikasikan yang bersifat deskriptif seperti proses suatu langkah kerja, formula suatu resep, pengertian-pengertian tentang suatu konsep yang beragam, karakteristik suatu barang dan jasa, gambar-gambar, gaya-gaya, tata cara suatu budaya, model fisik suatu artefak dan lain sebagainya.

Menurut Sukmadinata (2011, hlm.73), penelitian deskriptif kualitatif ditujukan untuk mendeskripsikan dan menggambarkan fenomena-fenomena yang ada, baik bersifat alamiah maupun rekayasa manusia, yang lebih memperhatikan mengenai karakteristik, kualitas, keterkaitan antar kegiatan. Selain itu, penelitian deskriptif tidak memberikan perlakuan, manipulasi atau pengubahan pada data yang diteliti, melainkan menggambarkan suatu kondisi yang apa adanya. Satu-satunya perlakuan yang diberikan hanyalah penelitian itu sendiri, yang dilakukan melalui observasi, wawancara, dan dokumentasi.

Dari definisi di atas dapat penulis simpulkan bahwa penelitian deskriptif kualitatif merupakan rangkaian kegiatan untuk memperoleh data dan mendeskripsikannya dengan apa adanya.

\section{Teknik Pengambilan Data}

Teknik pengambilan data yang digunakan dalam penelitian ini merupakan metode pengambilan data deskriptif kualitatif, yaitu dengan cara sebagai berikut :

1. Observasi

Observasi merupakan tindakan secara aktif dan penuh perhatian untuk menemukan fakta.

2. Wawancara

Menurut Sugiyono (2011, hlm.317) wawancara digunakan sebagai teknik pengumpulan data apabila peneliti ingin melakukan studi pendahuluan untuk menemukan permasalahan yang harus diteliti, dan juga apabila peneliti ingin mengetahui hal-hal dari responden yang lebih mendalam. Peneliti mengumpulkan data dengan wawancara tidak terstruktur dimana dalam wawancara ini peneliti bebas bertanya dan tidak menggunakan pedoman wawancara yang tersusun sistematis. Pedoman dalam jenis wawancara ini hanyalah berupa garisgaris besar permasalahan yang akan ditanyakan, sehingga peneliti lebih banyak memperoleh atau mendengarkan informasi dan pendapat yang diceritakan oleh responden. Wawancara dalam penelitian ini dilakukan dengan Bapak Ngadiman selaku pengelola Rumah Sandi dan juga wawancara terhadap pengunjung Rumah Sandi.

3. Studi Pustaka

Studi pustaka merupakan pengumpulan data dan informasi yang ada melalui sumber-sumber terpercaya dalam perpustakaan yang berhubungan dengan objek penelitian. Data yang diperoleh bertujuan untuk mengelola sumber tersebut menjadi pendukung landasan penelitian.

\section{Analisis Data}

Pendekatan penelitian yang digunakan yakni pendekatan kualitatif. Untuk mengetahui strategi yang dapat digunakan sebagai pengembangan situs Rumah Sandi agar situs Rumah Sandi dapat berfungsi secara optimal yaitu dengan cara menganalisis lingkungan internal dan eksternal. Sumber data primer berupa hasil wawancara dengan Bapak Ngadiman yang saat ini menjadi pengelola Rumah Sandi. Data sekunder dalam penelitian ini berupa dokumen tertulis, gambar dan foto. 
Perumusan strategi dilakukan dengan mengoptimalkan kekuatan dan memanfaatkan peluang yang ada.

\section{HASIL DAN PEMBAHASAN}

\section{Daya Tarik Wisata}

a. Obyek daya tarik wisata (Attraction)

Keunikan dan daya tarik wisata di Rumah Sandi yaitu:

1) Situs Rumah Sandi

Bangunan Rumah Sandi terletak di Dusun Dukuh, Desa Purwoharjo, Kecamatan Samigaluh, Kabupaten Kulon Progo. Dengan luas bangunan kurang lebih $118 \mathrm{~m}^{2}$, dengan luas tanah $1190 \mathrm{~m}^{2}$. Rumah Sandi terdiri dari dua bangunan yang dijadikan satu yaitu bangunan bagian depan dan bangunan bagian belakang. Bangunan depan merupakan bangunan yang dibangun pada tahun 1970, sedangkan bangunan belakang merupakan bangunan lama yang dahulu digunakan sebagai Rumah Sandi. Berdasarkan hasil Wawancara dengan Bapak Ngadiman selaku pengelola Rumah Sandi yang merupakan putra dari Bapak Ponijan (cucu dari Bapak Merto Setomo), Dusun Dukuh menjadi salah satu tempat penting dalam usaha melakukan taktik perang gerilya, dan juga merupakan bagian dari eksistensi persandian nasional yang mengawal perjuangan kemerdekaan RI. Setelah Belanda melanggar perjanjian Renvile dan menyerang kantor Sandi Negara Yogyakarta pada tanggal 19 Desember 1948, beberapa personil berhasil selamat, diantaranya Letnan II Soemarkidjo dan Letnan Muda Soedijatmo yang pergi ke desa Dekso. Di daerah dekat dekso terdapat markas kepala staf angkatan perang (KSAP TB Simatupang), yang berkedudukan di Desa Banaran (sekitar 5Km dari Dekso). Semua instansi pemerintah mengevakuasi diri mereka dari
Yogyakarta. Agresi militer Belanda tersebut membuat situasi pemerintahan di Yogyakarta tidak stabil. Hal yang sama berlaku untuk dinas Code yang harus memindahkan kantor mereka yang berada di jalan Batanawarsa 32 (sekarang jalan I Dewa Nyoman Oka Yogyakarta). Selang beberapa hari Roebiono Kertapati, Letnan II Harjoko dan Wijanarko yang bermaksud meneruskan perjalanan ke Jawa Barat tiba di Dekso. Dalam rangka mengadakan hubungan code maka Roebiono Kertopati memerintahkan agar CDO (petugas sandi) menyebar, dan mengevakuasi dokumen kode dengan mereka. Roebiono Kertopati menentukan tugas, Letnan II Soemarkidjo dan letnan Muda Soedijatmo tinggal di Dekso kemudian mendirikan bagian code yang berkedudukan di bawah PHB Angkatan Perang yang kemudian pindah di desa Dukuh. Roebiono Kertapati mengikuti perjalanan panjang ke Jawa Barat, beberapa CDO berjalan ke barat menuju Desa Dekso, Samigaluh Kulon Progo. Desa ini dipilih karena sangat strategis dengan perisai Sungai Progo di timur, dan Sungai Bogowonto di Barat. Mereka menemukan sebuah rumah yang aman untuk bersembunyi dari Belanda. Di rumah ini CDO melakukan semua kegiatan pengkodean. Markas Sandi Negara di Dusun Dukuh membuat pemancarpemancar kecil yang disambungkan dengan pemancar radio PHB PC-2 yang ada di Banaran, Playen, Gunung Kidul dan Balong. Berbagai komunikasi tersebut dapat direlay melalui pemancar radio melalui radio rimbu (rimbu radio) dan dapat diterima sampai ke Jakarta, Sumatera dan New Delhi. Rumah ini juga digunakan untuk mengumpulkan informasi/ berita dari dalam dan luar 
negeri. Rumah ini merupakan rumah milik bapak Merto Setomo dan digunakan sebagai ruang enkripsi darurat ketika agresi militer Belanda II menyerang pada tahun 1948. Bapak Ponijan yang merupakan anak dari bapak Merto Setomo menjadi utusan untuk membantu CDO menyampaikan pesan rahasia tersebut. Sementara itu, sistem komunikasi yang digunakan oleh kementerian pertahanan yaitu melalui kurir, termasuk petugas sandi di Dekso, Letnan II Soedijatmo dan Letnan II Soemarkidjo. Selain itu, Rumah Sandi Dukuh juga digunakan sebagai tempat pemeriksaan bagi para prajurit Indonesia yang hendak menemui Wakil Staf Angkatan darat, Letnan Kolonel T.B Simatupang di Banaran. Hal tersebut dilakukan untuk memastikan bahwa orang yang akan bertemu dengan Letnan Kolonel T.B Simatupang bukanlah seorang mata-mata.

Hubungan komunikasi code tersebut berjalan sampai kembalinya Yogyakarta ke pangkuan Republik Indonesia, paska persetujuan Konferensi Meja Bundar (KMB) dapat dikatakan merupakan titik pengakuan kedaulatan RI oleh Belanda. Rumah Sandi dapat dilihat pada gambar berikut ini:

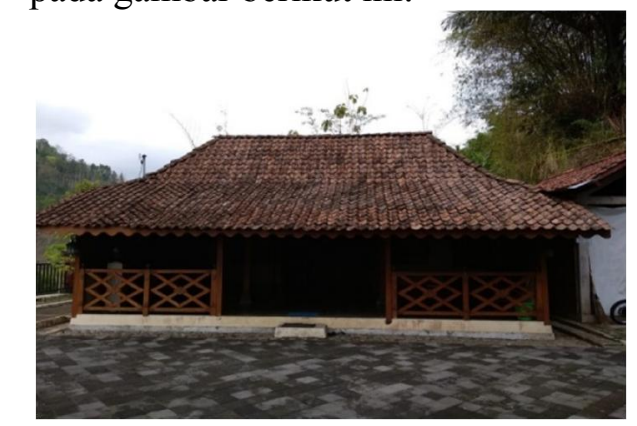

Sumber: Dokumentasi Peneliti (2018)

Gambar 1. Rumah Sandi
2) Replika dan peninggalan bersejarah

Pengiriman pesan rahasia dilakukan menggunakan buku kode $\mathrm{C}$ yang merupakan sandi tulisan Pak Roebiono. Bapak Roebiono Kertapati disebut bapak Sandi karena telah mengarang 10.000 kata kode Sandi. Saat ini tulisan Sandi tersebut berada di Museum Sandi Yogyakarta, saat ini yang ada di Rumah Sandi dusun Dukuh hanya sandi caesar yang saat itu cara membacanya sesuai dengan kesepakatan oleh petugas pengkodean, misal huruf $\mathrm{B}$ dibaca $\mathrm{A}$, huruf $\mathrm{C}$ dibaca $\mathrm{B}$ dan sebagainya.

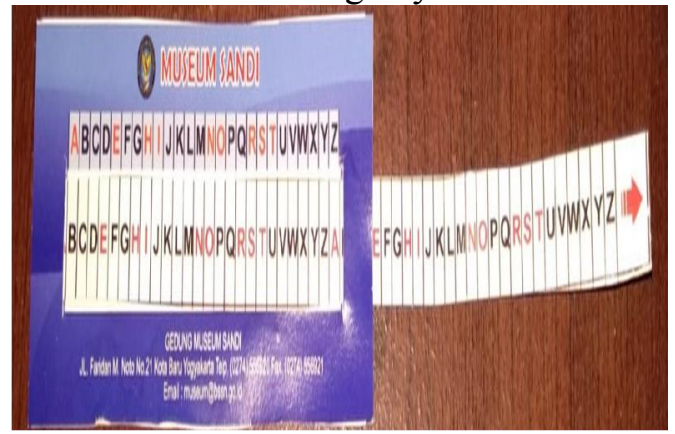

Sumber: Rumah Sandi (2018)

Gambar 2. Sandi Caesar

Di Rumah Sandi ini pengunjung juga dapat melihat replika Rumah Sandi, peta perjuangan, amben panjang yang digunakan untuk istirahat para penyandi dalam melakukan pengkodean dan membuka berita rahasia, alu dan lumpang yang merupakan salah satu perangkat memasak untuk mendukung logistik personil sandi selama perjuangan. 


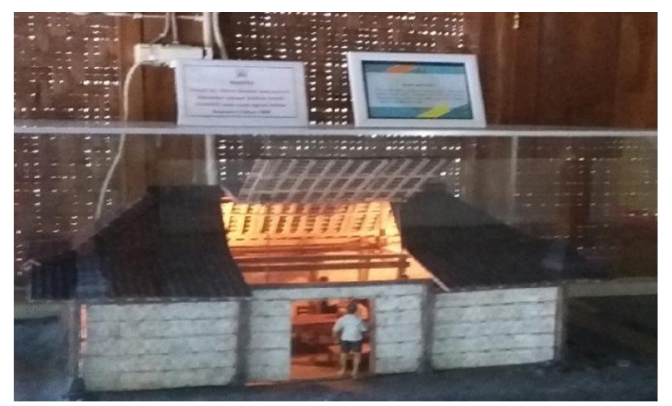

(a)

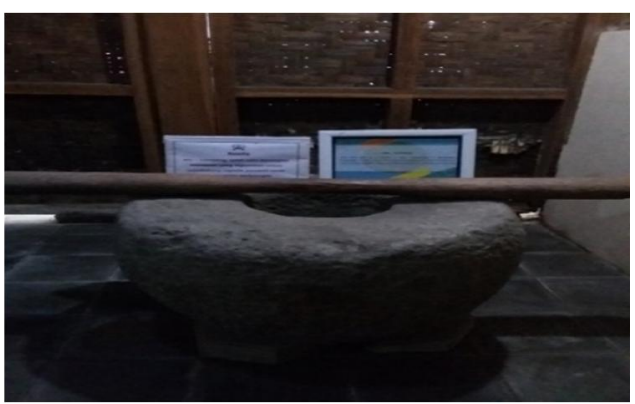

(b)

Sumber: Dokumentasi Peneliti 2018

Gambar 3 (a) dan (b). Replika Dan Peninggalan Sejarah

3) Pegunungan Menoreh

Pegunungan Menoreh terletak di wilayah barat laut Kabupaten Kulon Progo, sebelah timur Kabupaten Purworejo, dan sebagian Kabupaten Magelang. Perbukitan ini terbentuk dari karang yang memanjang dari wilayah Bagelen ke utara hingga mencapai bagian barat Kota Magelang. Perbukitan Menoreh ini dikenal sebagai basis pertahanan Pangeran Diponegoro bersama para pengikutnya dalam perang melawan HindiaBelanda pada tahun 1825-1830. Pegunungan Menoreh memiliki berbagai fungsi bagi masyarakat yang tinggal di sekitarnya, yaitu:

a) Secara hidrologis sebagai tangkapan hujan.

b) Secara geologis, proses-proses karstifikasi menghasilkan bentukan-bentukan alam yang unik.

c) Secara biologis dan ekologis keanekaragaman hayati setidaknya ada 47 jenis burung, dan keberadaan jenis kupu-kupu Troides Helena dan $T$. Amphrysus. 2 Jenis kelelawar Nycteris Javanica dan Rhinolophus Canuti.

d) Secara arkeologis, pegunungan Menoreh sangat bernilai dengan keberadaan Gua saplawan sebagai satu-satunya gua di Menoreh yang memiliki situs purbakala dangan penemuan arca emas, penemuan Lingga dan Yoni serta tulisan Jawa Kuno pada dinding Gua.

e) Fungsi ekonomis, yaitu pendapatan yang didapat dari hasil perkebunan, pertanian dan peternakan dan kontribusi yang cukup besar dari kegiatan wisata.

Indah dan sejuknya pegunungan Menoreh ini memberikan daya tarik wisata di Rumah Sandi. Pengunjung Rumah Sandi dapat menikmati keindahan alam pegunungan yang tidak bisa didapatkan di lingkungan perkotaan yang padat akan penduduk.

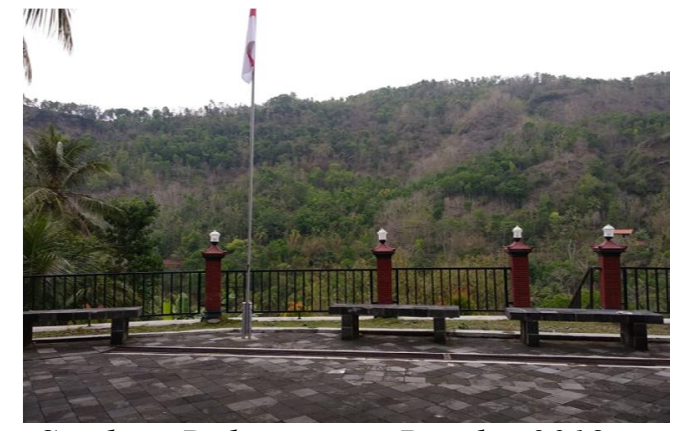

Sumber: Dokumentasi Peneliti 2018

Gambar 4. Pegunungan Menoreh

b. Amenitas (Amenities)

Amenitas (Amenities) mencakup fasilitas penunjang dan pendukung wisata di Rumah Sandi yaitu:

1) Taman bermain anak

Untuk menarik minat pengunjung terhadap Rumah Sandi, pada halaman depan Rumah Sandi dibuat taman bermain untuk anak-anak, kolam ikan, 
taman bunga dan gazebo. Dengan adanya fasilitas ini anak-anak menjadi tertarik untuk bermain sambil belajar sejarah di Rumah Sandi. Selain anakanak, remaja dan orang tua pun bisa berkunjung ke Rumah Sandi sambil berselfie ria di taman bunga dan bersantai di gazebo yang telah disediakan.

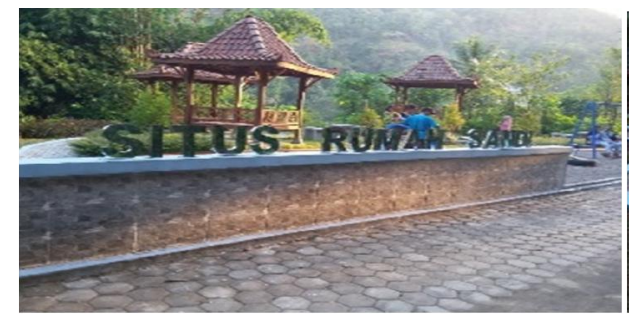

(a)

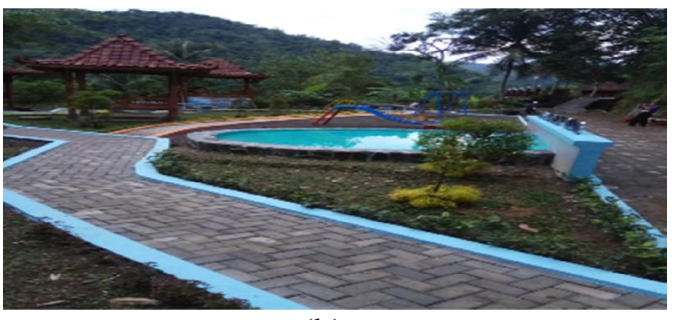

(b)

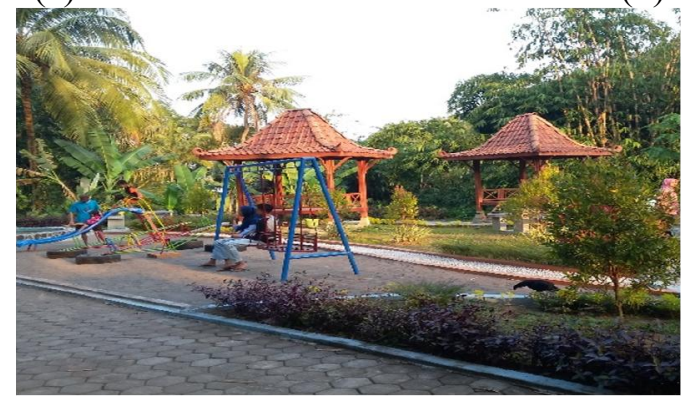

(c)

Sumber: Dokumentasi Peneliti 2018

Gambar 5 (a), (b), dan (c). Taman Dan Tempat Bermain

2) Monumen SANAPATI

Di sebelah taman juga terdapat monumen SANAPATI. Monumen SANAPATI didirikan dan diresmikan sebagai tanda peringatan 50 tahun terbentuknya persandian Republik Indonesia di Yogyakarta. Monumen SANAPATI ini berupa patung tugu berbentuk segi tiga, berujung lancip mirip piramida.

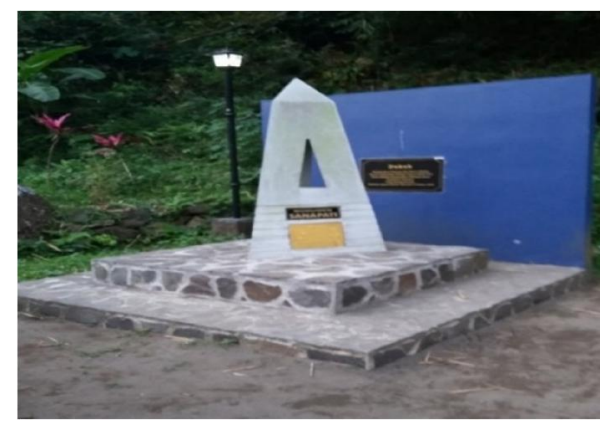

Sumber: Dokumentasi Peneliti 2018

Gambar 6. Monumen SANAPATI di Rumah Sandi c. Aksesibilitas (aksesibility)

Lokasi Rumah Sandi mudah dikunjungi oleh wisatawan dengan lokasi tidak jauh dari jalan utama dengan nama jalan persandian. Jalan ini dilengkapi dengan petunjuk arah, dengan akses jalan yang mudah dilewati motor, mobil maupun bus dengan area parkir yang luas.

2. Faktor Pendukung dan Penghambat

a. Faktor pendukung

Faktor pendukung pada lingkungan eksternal Rumah Sandi, yaitu:

1) Peran pemerintah melalui kebijakan wajib kunjung museum.

2) Kerjasama antara dinas kebudayaan Propinsi DIY dan Kabupaten Kulon Progo dengan menyelenggarakan kegiatan di Rumah Sandi seperti mengadakan pagelaran wayang pada saat ulang tahun Rumah Sandi sebagai upaya mengenalkan Rumah Sandi kepada masyarakat. 
3) Infrastruktur jalan menuju Rumah Sandi yang baik.

Faktor pendukung di lingkungan internal Rumah Sandi yaitu:

1) Adanya anggaran pembangunan dari Museum Sandi Yogyakarta membuat pembangunan di Rumah Sandi sangat pesat.

2) Adanya pembinaan untuk pengelola Rumah Sandi dari Museum Sandi Yogyakarta membuat pemandu dapat memberikan pelayanan dengan baik.

3) Adanya website yang dapat membantu memberikan informasi kepada calon pengunjung.

4) Pemandu sangat ramah dalam melayani pengunjung.

5) Kawasan Rumah Sandi yang sangat indah terletak di pegunungan Menoreh sehingga memberikan daya tarik wisata di Rumah Sandi.

b. Faktor penghambat

Faktor penghambat di lingkungan internal Rumah Sandi yaitu:

1) Kurangnya sumber daya yang menjadi pengelola situs Rumah Sandi, jika pengunjung sekitar 1020 orang pemanduan dilakukan oleh Bapak Ngadiman, akan tetapi jika pengunjung banyak pemanduan dibantu oleh pemandu dari museum Sandi Yogyakarta.

2) Sebagian benda peninggalan sudah dibawa ke museum Sandi Yogyakarta sehingga pengunjung harus mengunjungi dua tempat jika ingin mempelajari Sandi secara optimal.

Faktor penghambat pada lingkungan eksternal yaitu:

1) Kurangnya kesadaran dari masyarakat terhadap pelestarian peninggalan bersejarah.

2) Masyarakat kurang memahami mengenai situs Rumah Sandi.
3. Strategi yang dapat disusun dalam pengembangan situs Rumah Sandi Strategi yang dapat disusun dalam pengembangan situs Rumah Sandi yaitu:

a. Penambahan jumlah SDM yang terspesialisasi sesuai kompetensi yang dimiliki dengan:

1) Mendatangkan tenaga kompeten seperti juru pelihara situs.

2) Merekrut pemandu serta tenaga lainnya sesuai dengan kebutuhan yang ditempatkan di kantor situs Rumah Sandi.

3) Memberikan lapangan pekerjaan untuk masyarakat yang tinggal di sekitar kawasan Rumah Sandi agar dapat bekerjasama dalam melestarikan budaya yang ada.

b. Pengidentifikasian para stakeholder sebagai mitra dalam pengembangan situs Rumah Sandi agar mampu beradaptasi dan dapat memenuhi kebutuhan masyarakat secara optimal melalui:

1) Bekerjasama dengan pihak pemerintah Kabupaten Kulon Progo secara berkelanjutan untuk pengembangan kawasan Situs Rumah Sandi seperti mengembangkan kuliner dan pusat oleh-oleh di sekitar Rumah Sandi agar dapat meningkatkan kunjungan dan dapat melestarikan kuliner setempat.

2) Bekerjasama dengan perguruan tinggi untuk penelitian dan pengabdian masyarakat dalam pengembangan Rumah Sandi.

3) Bekerjasama dengan instansi pendidikan untuk meningkatkan minat kunjung ke situs Rumah Sandi.

c. Peningkatan kesadaran masyarakat terkait situs Rumah Sandi dan pelestariannya melalui:

1) Menyusun program kegiatan untuk memberikan pemahaman dan kesadaran masyarakat mengenai situs Rumah Sandi dan 
bangunan serta benda-benda peninggalannya.

2) Menumbuhkan kesadaran masyarakat agar ikut berperan dalam melestarikan peninggalan dan menjunjung nilai-nilai sejarah.

3) Meningkatkan peran pengelola Rumah Sandi dalam sosialisasi keberadaan Rumah Sandi.

d. Peningkatan kualitas pelayanan dengan merencanakan dan merumuskan sesuai kebutuhan masyarakat melalui:

1) Dibuatkan alur kunjungan agar pengunjung lebih memahami informasi yang disampaikan pemandu.

2) Menambah dan menyediakan SDM yang berkompeten pada bidangnya masing-masing.

3) Memanfaatkan website Rumah Sandi secara optimal sebagai media promosi Rumah Sandi.

e. Peningkatan kemampuan pemandu melalui:

1) Diklat dengan mendatangkan ahli.

2) Berkunjung untuk berbagi pengalaman dengan daerah lain yang telah berhasil dalam penanganan pemanduan.

\section{KESIMPULAN}

1. Daya Tarik Wisata Rumah Sandi yaitu:

a. Attraction berupa Situs Rumah Sandi, replika dan peninggalan sejarah, serta keindahan alam pegunungan Menoreh.

b. Amenitas berupa taman dan tempat bermain, serta museum SANAPATI.

c. Aksesibilitas dengan akses jalan yang baik dan tempat parkir yang memadai.

2. Faktor Pendukung dan Penghambat

a. Faktor Pendukung

Faktor pendukung pada lingkungan eksternal yaitu

1) Peran pemerintah melalui kebijakan wajib kunjung museum.

2) Dinas kebudayaan Propinsi DIY dan Kabupaten Kulon Progo dengan menyelenggarakan

kegiatan di Rumah Sandi untuk mengenalkan Rumah Sandi kepada masyarakat.

3) Infrastruktur jalan menuju Rumah Sandi yang baik.

Faktor pendukung lingkungan internal Rumah Sandi yaitu:

1) Adanya anggaran dari museum Sandi Yogyakarta membuat pembangunan di Situs Rumah Sandi sangat pesat.

2) Adanya pembinaan untuk pengelola Rumah Sandi dari Museum Sandi Yogyakarta membuat pemandu dapat memberikan pelayanan dengan baik.

3) Adanya Website yang dapat membantu memberikan informasi kepada calon pengunjung.

4) Pemandu sangat ramah dalam melayani pengunjung.

5) Kawasan Rumah Sandi yang sangat indah terletak di pegunungan Menoreh sehingga memberikan daya tarik wisata di Rumah Sandi.

b. Faktor Penghambat

Faktor penghambat di lingkungan internal Rumah Sandi yaitu:

1) Kurangnya sumber daya yang menjadi pengelola situs Rumah Sandi.

2) Sebagian benda peninggalan sudah dibawa ke museum Sandi Yogyakarta sehingga pengunjung harus mengunjungi dua tempat jika ingin mempelajari Sandi secara optimal.

Faktor penghambat pada lingkungan eksternal Rumah Sandi yaitu:

1) Kurangnya kesadaran dari masyarakat terhadap pelestarian peninggalan bersejarah.

2) Masyarakat kurang memahami mengenai situs Rumah sandi

3. Strategi yang dapat disusun dalam pengembanagn situs Rumah Sandi yaitu: 
Temoteus Prasetyo Hadi Atmoko: Pengembangan Wisata Sebagai Daya Tarik Situs Rumah Sandi Di Perbukitan Menoreh Kulon Progo

a. Penambahan jumlah SDM yang terspesialisasi sesuai kompetensi yang dimiliki.

b. Pengidentifikasian para stakeholder sebagai mitra dalam pengembangan situs Rumah Sandi agar mampu beradaptasi dan dapat memenuhi kebutuhan pendidikan secara optimal.

c. Peningkatan kesadaran masyarakat terkait situs Rumah Sandi dan pelestariannya.

d. Peningkatan kualitas pelayanan dengan merencanakan dan merumuskan sesuai kebutuhan pendidikan.

Saran yang dapat diberikan:

1. Pengelola hendaknya melakukan kerjasama dengan pihak travel agent, dan pelaku wisata agar dapat meningkatkan kunjungan wisata Rumah Sandi dengan berbagai segmen.

2. Hendaknya ditambah jumlah SDM pengelola situs Rumah Sandi agar pemberian pelayanan kepada masyarakat lebih optimal.

\section{DAFTAR PUSTAKA}

. (n.d). Berkunjung ke Museum Cara Mudah Belajar Sejarah. [Online], Diakses dari https://www.harianhaluan.com/mobile/ detailberita/48846/berkunjung-kemuseum-cara-mudah-belajar-sejarah.

Hadiwijoyo, Suryo Sakti. (2012). Perencanaan Pariwisata Pedesaan
Berbasis Masyarakat (Sebuah Pendekatan Konsep). Yogyakarta : Graha Ilmu.

Komariah, AAn \& Satori, Djam'an. (2011). Metode Penelitian Kualitatif. Bandung: Alfabeta.

Purnawan, Ni Luh. (2012). Wisata Edukasi Budaya Bali. Jurnal Ngayah, 3(4), Undiksha.

Sinaga, Supriono. (2010). Potensi dan Pengembangan Objek Wisata di Kabupaten Tapanuli Tengah. Universitas Sumatera Utara.

Sugiono. (2011). Metode Penelitian Pendidikan (Pendekatan Kuantitatif, Kualitatif, dan R\&D). Bandung: Alfabeta.

Sukmadinata. (2011). Metode penelitian Pendidikan. Bandung: Remaja Rosda Karya.

Sunaryo, Bambang. (2013). Kebijakan Pembangunan Destinasi Pariwisata, Konsep dan Aplikasinyadi Indonesia. Yogyakarta: Gava Media.

Tim Pengabdian Masyarakat STP ARS Internasional dan Akpar BSI Bandung. (2017). Buku Panduan Wisata Edukasi. Bandung: STP ARS Internasional.

UU Kepariwisataan no 10 tahun 2009. Widyaningsih, Heni. (2013). Pengembangan Pariwisata Wilayah Palbapang Mendut sebagai daya Tarik Wisata di Kabupaten Magelang. BSI: Konferensi Nasional Ilmu Sosial dan Teknologi, 1(1). 